\title{
Efeitos do uso de areia de praia nas propriedades de argamassas mistas: análise da variação granulométrica
}

\section{Effects of the use of beach sand on mixed mortar properties: analysis of granulometric variation}

Ruan Landolfo da Silva Ferreira ${ }^{1}$, Ilana Maria da Silva Barros ${ }^{1}$, Túlio Cesar de Souza Costa ${ }^{1}$, Mauricéia Medeiros ${ }^{1}$, Maria das Vitórias Vieira Almeida de Sá Arnaldo Manoel Pereira Carneiro ${ }^{3}$

\footnotetext{
${ }^{1}$ PEC/UFRN, R. das Engenharias, Lagoa Nova, CEP: 59078-970, Natal, Rio Grande do Norte, Brasil.

${ }^{2}$ UFRN, Departamento de Engenharia Civil, Natal, Rio Grande do Norte, Brasil.

${ }^{3}$ UFPE, Departamento de Engenharia Civil, Recife, Pernambuco, Brasil. e-mail: ruan_landolfo@ hotmail.com, ilanabarros@hotmail.com, tuliocosta@outlook.com, mauriceia21@hotmail.com, ampc@ufpe.br, vitoria@ct.ufrn.br
}

\begin{abstract}
RESUMO
Devido ao alto consumo de areia de rio na construção civil e sua extração abusiva, cujos resultados são a geração de diversos impactos ambientais, este estudo analisa a influência da utilização de areia de praia em substituição à areia proveniente de leito de rio na produção de argamassas de revestimento. A partir da areia de rio, foram confeccionadas outras duas variações: a primeira possuía $70 \%$ de fração fina (partículas $<1,18$ $\mathrm{mm}$ ) e $30 \%$ de fração média (partículas <2,36 mm); e a segunda, $60 \%$ de fração fina e $40 \%$ de fração média. Foram utilizados cimento Portland (CP II-Z) e cal hidratada (tipo CHI) como aglutinantes em proporção constante (em massa) de 1:3 (aglomerante/agregado), com variações de 1:1:6 e 1:2:9 (cimento, cal e agregado). O programa experimental consistiu na análise dos agregados (por meio da granulometria e da massa unitária) e das argamassas no estado fresco e endurecido. No estado fresco foi determinada a relação entre o consumo de água e a consistência e a densidade de massa aparente. No estado endurecido determinou-se o coeficiente de capilaridade, a taxa de variação de massa e a resistência mecânica à compressão e à tração. Os resultados indicaram que a areia de praia e a de rio apresentam comportamentos físicos semelhantes, embora a primeira possua distribuição granulométrica mais uniforme e maior quantidade de finos, refletindo diretamente no desempenho das argamassas.
\end{abstract}

Palavras-chave: areia com sais, distribuição granulométrica, argamassas de revestimento.

\section{ABSTRACT}

Several environmental impacts are due to the high consumption of river sand in the construction industry. This study aims to analyze the influence of the use of beach sand in order to use river sand for mortar productions. From the river sand, two variations were made: the first one had $70 \%$ of fine fraction (particles $<1.18 \mathrm{~mm}$ ) and $30 \%$ of medium fraction (particles $<2.36 \mathrm{~mm}$ ); and the second, $60 \%$ fine fraction and $40 \%$ average fraction. Portland cement (CP II-Z-RS) and hydrated lime (CHI type) were used as constant and binder ratio (in weight) of 1:3 (binder/aggregate), with variations of 1:1:6 and 1:2:9 (cement, lime and aggregate). The experimental program consisted of the analysis of the aggregates (by means of the size distribution and the bulk density) and the mortars in the fresh and hardened state. In the fresh state, the relation between the water consumption and the consistency and bulk density was determined. In the hardened state, the capillary coefficient, the rate of mass change and the mechanical strength to compression and traction were determined. The results indicated that the beach and river sand presented similar physical behaviour, although the first one has a more uniform particle size distribution and a greater amount of fines, directly reflecting the performance of the mortars.

Keywords: sand with salts, particle size distribution, coating mortars. 


\section{INTRODUÇÃO}

Nas últimas décadas, em função do crescimento urbano e econômico, o consumo de recursos naturais e energia aumentou consideravelmente. Estima-se que $40 \%$ dos recursos naturais sejam consumidos pela construção civil [1], o que faz com que essa seja considerada uma das indústrias que mais contribui para alterar o meio ambiente. A previsão é que a demanda por materiais atinja, no mínimo, o dobro dos níveis atuais até 2050 [2].

No Brasil, cerca de $1 / 3$ dos recursos naturais é destinado à produção de materiais cimentícios [3]. $\mathrm{O}$ consumo de agregados, por exemplo, gira em torno de 632 milhões de toneladas por ano, o que corresponde a cerca de 3,31 toneladas por habitantes [4]. Em particular, pode-se citar os agregados miúdos que, em 2013, atingiram um consumo de aproximadamente 377 milhões de toneladas [5]. Agrava ainda mais esse cenário o fato de que mais de $90 \%$ de toda a areia consumida no País seja extraída de leitos de rios [6], e o resultado disso é a geração de diversos problemas ecológicos e ambientais.

Nessa perspectiva, atualmente, as fontes de agregados naturais estão em processo de esgotamento e sua extração, incontrolada e abusiva, também pode causar consequências nocivas ao ecossistema do planeta [7, 8, 9], como a modificação do equilíbrio biológico [7, 10] e da microbiota do solo [11].

Em consequência disso, o uso irracional dos recursos naturais na construção ameaça o meio ambiente. A valorização de materiais locais e resíduos industriais pode contribuir para a redução de custos e a preservação do meio ambiente [12]. Por essas razões, é necessário otimizar o consumo dos agregados, assim como buscar mais alternativas para sua substituição com o objetivo de minimizar os impactos negativos ao meio ambiente decorrentes de sua extração e consumo desordenado.

A areia contendo sais solúveis em sua composição, seja proveniente de dunas, praia ou mar, tem sido estudada como substituto dos agregados naturais devido ao esgotamento de fontes naturais, principalmente junto aos centros urbanos e às zonas costeiras bem desenvolvidas - o que impulsiona a extração destes materiais para regiões cada vez mais distantes [7, 13]. Estudos [7, 12, 13, 14, 15, 16] mostraram que é viável a utilização desse tipo de areia como material de construção, embora exibam propriedades inferiores aos materiais de referência e sua utilização esteja condicionada ao tipo de aplicação e ao ambiente de exposição. A esse respeito, na Grã-Bretanha a areia de mar tem sido utilizada na produção de concreto há várias décadas. Ela possui baixo custo, pouca quantidade de argila, frações de tamanho desejadas e abundantes vantagens de armazenamento em comparação com a areia artificial e reciclada $[15,17]$. Comparando-a com a areia de rio, embora ambas possuam a mesma origem geológica, a principal diferença é que a de praia possui conteúdo de sais e de matéria orgânica $[7,14]$ que, em excesso, poderá afetar o desempenho e a durabilidade dos materiais cimentícios. Nesses casos, faz-se necessária a realização de algum tipo de tratamento, como, por exemplo, lavagem com água doce [14], de modo que permita a remoção, principalmente, dos sais. Tal procedimento, muitas vezes, torna-se uma alternativa inviável tendo em vista os custos e a escassez de água doce.

LIMEIRA et al. [15] observaram que o conteúdo de cloreto e sulfato não influencia o comportamento das pastas quanto à trabalhabilidade. Por outro lado, esses componentes quando encontrados em teores consideráveis, devem ser determinados exaustivamente devido à sua influência na durabilidade dos materiais cimentícios. HUIGUANG et al. [13] demonstraram que a mistura cimentícia que possuía areia do mar apresentou uma melhor ligação entre a pasta de cimento e o agregado e, como consequência, a resistência à penetração de íons cloreto foi maior quando comparada às misturas constituídas de areia de rio comum.

Em relação às propriedades físicas desses agregados, LIMEIRA et al. [15] observaram que a principal influência da utilização de areia de praia (AP) em argamassas está relacionada com a distribuição do tamanho das partículas, e não com o conteúdo de cloretos presentes nesses agregados e que, portanto, não há interferência na trabalhabilidade e nas resistências à compressão desses materiais. BELFERRAG et al. [12] mostraram que areias de dunas, por possuírem granulometria fina, contribuem significativamente para a retração de materiais cimentícios.

Esses resultados demonstram o potencial da utilização de areias contendo sais em argamassas. Entretanto, atualmente, o número de estudos sobre esse tema é muito limitado, o que contribui para a não aceitação desses materiais no mercado da construção civil e, consequentemente, para a problemática ambiental, uma vez que não é dada a devida atenção a outros tipos de agregados que podem substituir os de leito de rio.

É importante destacar que os agregados miúdos (areias), ainda que se constituam na fração inerte, compõem o maior volume das argamassas e, portanto, influenciam significativamente as propriedades do produto no estado fresco e endurecido [18]. Tanto a origem quanto a distribuição do tamanho das partículas do agregado podem influenciar intrinsicamente as propriedades das argamassas, como porosidade, permeabilidade e resistência. Dessa forma, é imprescindível que seja realizada uma seleção adequada dos 
agregados a fim de produzir materiais com melhores desempenhos [4].

Tal influência é de grande interesse, uma vez que a microestrutura interna de argamassa à base de cimento se dá em função de sua porosidade e distribuição do tamanho dos poros (resultado de vazios entre grãos de areia e aqueles intrinsecamente presentes em produtos de cimentação). Assim, uma mudança no tamanho dos grãos de areia (o principal componente em peso e volume) deve ter um efeito drástico sobre a microestrutura de argamassa [19] e, por conseguinte, nas propriedades mecânicas, na porosidade, na hidratação dos materiais, bem como outras características [20].

Atualmente, o número de pesquisas sobre o uso de AP em argamassas é limitado, negligenciando seu potencial de utilização e contribuindo para a manutenção dos impactos ambientais causados pela extração de areia de rio. Além disso, a ausência de estudos que possam preencher as lacunas existentes sobre o tema, bem como contribuir para nortear futuras pesquisas e aumentar aceitação desses materiais alternativos na construção civil, colaboram ainda mais para a problemática ambiental.

A possibilidade de substituir os agregados obtidos de leito de rio constitui uma importante tarefa que, a longo prazo, contribui para mitigar os impactos ambientais e alcançar ambientes construídos sustentáveis e de baixo carbono. Dessa forma, neste trabalho, investiga-se a influência da utilização de AP em substituição a areia natural (AN) proveniente de leito de rio, assim como os efeitos de suas distribuições granulométricas nas propriedades físicas e mecânicas de argamassas à base de cal e cimento. Ressalta-se que a influência dos sais presentes na AP não será objeto de estudo deste artigo, cabendo ser abordado em estudos futuros.

\section{MATERIAIS E MÉTODOS}

\subsection{Materiais}

Os materiais utilizados foram cimento CP II-Z-32-RS (massa específica de $2,93 \mathrm{~g} / \mathrm{cm}^{3}$; superfície específica Blaine $4,362 \mathrm{~cm}^{2} / \mathrm{g}$ ) e cal hidratada do tipo CH-I (densidade aparente de $0,56 \mathrm{~g} / \mathrm{cm}^{3}$ ). A fração inerte foi composta por agregados miúdos de duas origens: areia natural oriunda do leito de rios (AN) de massa específica $2,62 \mathrm{~g} / \mathrm{cm}^{3}$ e areia de praia (AP) de massa específica $2,58 \mathrm{~g} / \mathrm{cm}^{3}$, ambas coletadas na região metropolitana de Natal/RN-Brasil.

As duas areias foram secas em estufa $(105 \pm 5){ }^{\circ} \mathrm{C}$ durante 72 horas e, posteriormente, resfriadas à temperatura ambiente. Após esse procedimento, foram confeccionadas duas variações da AN, sendo uma produzida com $70 \%$ de fração fina (partículas $<1,18 \mathrm{~mm}$ ) e $30 \%$ de fração média (partículas $<2,36 \mathrm{~mm}$ ), denominada de AN7030; e outra com 60\% e 40\% de fração fina e média, respectivamente, denominada de AN6040. O intuito da utilização de areias de diferentes tamanhos foi obter, ao misturá-las, o menor índice de vazios possível com base no ensaio piloto de massa unitária compactada (ABNT NBR NM 45 [21]).

\subsection{Métodos}

Ao partir de duas proporções em massa de cimento, cal e agregado - 1:2:9 (T1 - traço 1) e 1:1:6 (T2 - traço 2), foram produzidos seis tipos diferentes de argamassas, sendo que:

- $\quad$ AAP-T1: argamassa produzida com AP e com o T1;

- AAP-T2: argamassa produzida com AP e com o T2;

- AAN6040-T1: argamassa produzida com AN6040 e com o T1;

- AAN6040-T2: argamassa produzida com AN6040 e com o T2;

- AAN7030-T1: argamassa produzida com AN7030 e com o T1;

- AAN7030-T2: argamassa produzida com AN7030 e com o T2.

A quantidade de cada material utilizado para a produção das argamassas pode ser observada na Tabela 1. Para o cálculo do consumo de materiais foram utilizadas as densidades de massa das argamassas no estado fresco e relação água/cimento (a/c) para um espalhamento de $260 \mathrm{~mm}$ (ABNT NBR 13276 [22]), e os resultados são apresentados na seção 3.1.1 e 3.1.2.

A homogeneização dos materiais foi realizada em uma batedeira de eixo vertical com capacidade máxima de $3 \mathrm{~kg}$. Para a mistura adotou-se a seguinte sequência: primeiramente a adição da pasta de cal na batedeira, seguida do agregado e, após a homogeneização desses materiais, a adição do cimento. $\mathrm{O}$ tempo de mistura, após a adição do cimento, foi de aproximadamente 5 minutos. 
Tabela 1: Quantidade de cada material utilizado para a produção das argamassas.

\begin{tabular}{l|l|l|l|l|l}
\hline \multirow{2}{*}{ ARGAMASSA } & \multicolumn{2}{l|}{ AGLOMERANTES $(\mathbf{g})$} & \multicolumn{2}{l}{ AGREGADO MIÚDO $(\mathbf{g})$} \\
\cline { 2 - 6 } & CIMENTO & CAL & AN FINA & AN MÉDIA & AP \\
\hline AAP-T1 & 144,09 & 288,19 & - & - & 1296,85 \\
AAP-T2 & 211,86 & 211,86 & - & - & 1271,19 \\
AAN6040-T1 & 148,48 & 296,96 & 801,79 & 534,53 & - \\
AAN6040-T2 & 222,60 & 222,60 & 801,37 & 534,25 & - \\
AAN7030-T1 & 140,31 & 280,63 & 883,97 & 378,85 & - \\
AAN7030-T2 & 225,92 & 225,92 & 948,85 & 406,65 & - \\
\hline
\end{tabular}

A caracterização dos agregados e das argamassas foi realizada de acordo com as normas, condições e equipamentos apresentados na Tabela 2.

Tabela 2: Ensaios realizados para a caracterização das argamassas e suas respectivas normatizações.

\begin{tabular}{l|l|l}
\hline CARACTERIZAÇÃO & ENSAIOS & NORMATIZAÇÃO \\
\hline \multirow{2}{*}{ Agregados } & Composição granulométrica & ABNT NBR NM 248 [23] \\
\cline { 2 - 3 } & Massa unitária & ABNT NBR NM 45 [21] \\
\hline \multirow{2}{*}{ Argamassas no estado fresco } & Consumo de água & ABNT NBR 13276 [22] \\
\cline { 2 - 3 } & Densidade de massa & ABNT NBR 13278 [24] \\
\hline \multirow{3}{*}{ Argamassas no estado endurecido } & Absorção de água por capilaridade & ABNT NBR 15259 [25] \\
\cline { 2 - 3 } & Taxa de variação de massa & CSTB [26] \\
\cline { 2 - 3 } & Resistência à tração na flexão e à compressão & ABNT NBR 13279 [27] \\
\hline
\end{tabular}

Para a realização dos ensaios no estado endurecido foram moldados três corpos de prova prismáticos (40x40x160) mm para cada ensaio, de acordo com a ABNT NBR 13279 [27]. Os mesmos foram mantidos ao ar livre à temperatura ambiente, sendo desmoldados após 48 horas; e permanecendo nessas condições durante 28 dias.

\section{RESULTADOS E DISCUSSÕES}

\subsection{Caracterização dos agregados}

Os resultados referentes à composição granulométrica das areias estão dispostos na Tabela 3, e suas respectivas curvas granulométricas podem ser vistas na Figura 1.

Tabela 3: Distribuição granulométrica das areias.

\begin{tabular}{l|l|l|l|l|l|l}
\hline PENEIRA (mm) & \multicolumn{4}{l}{ \% RETIDA ACUMULADA } & \multicolumn{2}{l}{ \% QUE PASSA } \\
\hline 4,75 & AP & AN7030 & AN6040 & AP & AN7030 & AN6040 \\
\hline 2,36 & 0,0 & 0,0 & 0,0 & 100 & 100 & 100 \\
\hline 1,18 & 0,0 & 0,18 & 0,25 & 100 & 99,82 & 99,75 \\
\hline 0,6 & 0,03 & 4,06 & 6,74 & 99,97 & 95,94 & 93,26 \\
\hline 0,3 & 0,30 & 11,25 & 18,39 & 99,70 & 88,75 & 81,61 \\
\hline 0,15 & 20,68 & 44,32 & 53,46 & 79,32 & 55,68 & 46,54 \\
\hline 0,075 & 77,77 & 90,50 & 92,69 & 22,23 & 9,50 & 7,31 \\
\hline$<0,075$ & 99,52 & 98,52 & 99,47 & 0,48 & 1,48 & 0,53 \\
\hline
\end{tabular}

Com relação aos limites de norma, apenas AN6040 aproximou-se dos intervalos recomendados pela ASTM C-144-03 [28] e ABNT NBR 7211 [29], como se verifica na Figura 1. As demais areias estão fora dos intervalos normativos e, portanto, não atendem aos requisitos para agregados miúdos naturais empregados em argamassas e concretos, respectivamente. Esses resultados mostram que as normas supracitadas não 
contemplam todo o universo de areias utilizadas no Brasil.

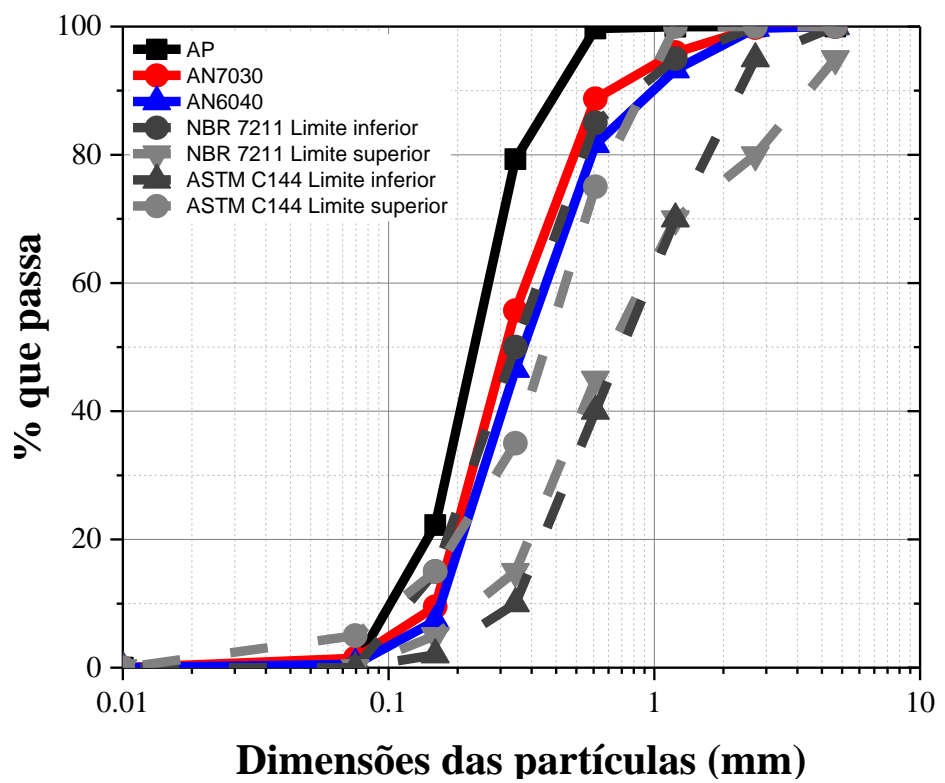

Figura 1: Curva granulométrica da areia de praia e das areias naturais.

Ao analisar a curva granulométrica das areias estudadas (Figura 1), nota-se que as curvas das areias naturais possuem retas com menor ângulo de inclinação, sugerindo, a princípio, que suas composições possuem melhor distribuição de grãos. Tal fato pode ser confirmado por meio do coeficiente de uniformidade $\left(C_{u n}\right)$ oriundo da mecânica dos solos e definido pela Eq. 1, descrita a seguir:

$$
C_{u n}=\frac{D_{60}}{D_{10}}
$$

Onde:

$D_{60}$ - Diâmetro correspondente a $60 \%$ passante nas peneiras;

$D_{10}$ - Diâmetro correspondente a $10 \%$ passante nas peneiras.

Os coeficientes de uniformidade dessas areias são apresentados na Tabela 4. As areias estudadas são classificadas com base no coeficiente de uniformidade como sendo muito uniformes, segundo a classificação indicada por estudos anteriores [30;31]. Entretanto, a AN6040 foi a que apresentou maior coeficiente de uniformidade e, portanto, possui melhor distribuição dos grãos (isto é, distribuição mais contínua) quando comparada com as demais. Sugere-se ainda que a melhor distribuição dos grãos favorece o empacotamento das partículas e, por conseguinte, influencia as propriedades das argamassas no estado fresco e endurecido.

Tabela 4: Coeficientes de uniformidade das AN e AP.

\begin{tabular}{l|l}
\hline AREIAS & $\boldsymbol{c}_{\boldsymbol{u n}}$ \\
\hline AP & 2,31 \\
\hline AN7030 & 2,43 \\
\hline AN6040 & 2,59 \\
\hline
\end{tabular}

A AP obteve menor coeficiente de uniformidade, o que a caracteriza, em comparação com as demais areias, como pior distribuição granulométrica. Esses resultados são semelhantes aos obtidos por BELFERRAG et al. [12], cujas areias provenientes de dunas apresentaram comportamento granulométrico descontínuo. Outro aspecto importante, devido a sua influência nas propriedades de argamassas, é a quantidade de finos (partículas com dimensões $<0,15 \mathrm{~mm}$ ) presentes na composição de grãos dos agregados. Antes de mais nada, é importante ressaltar que o conteúdo de finos deve ser restrito, pois, em quantidades 
excessivas, pode reduzir significativamente a resistência e durabilidade de argamassas [32].

De acordo com os resultados exibidos na Tabela 3, verifica-se que a AP possui mais que o dobro da quantidade de finos (22,71\%) dos agregados naturais AN7030 (10,97\%) e AN6040 (7,84\%). Esses resultados corroboram com outros estudos [7]. LIMEIRA et al. [7] observaram que as areias marinhas apresentam elevados teores de finos quando comparadas com areias calcárias e ressaltaram que elevados teores de finos são indesejáveis em AP, tendo em vista que quanto menor o tamanho dos grãos, maior a presença de contaminantes. Estes componentes indesejáveis devem ser controlados (por exemplo, por intermédio de lavagem do agregado com água doce), pois, em quantidades excessivas, podem desencadear o surgimento de diferentes manifestações patológicas, como a corrosão do aço em estruturas de concreto armado $[7,14]$ e em argamassas armadas, ou argamassas que tenham seu uso destinado ao reparo dessas estruturas.

Em relação às propriedades físicas das areias estudadas, a Tabela 5 resume os principais resultados. Nota-se que a AP apresentou menores dimensão máxima característica, módulo de finura e massa unitária, o que era esperado tendo em vista seu comportamento granulométrico. As areias estudadas podem ser classificadas como finas, segundo a classificação baseada no módulo de finura [30]. Em termos práticos, essas areias são adequadas para serem utilizadas em argamassas de revestimento. É preciso ressaltar que o módulo de finura da AN6040 foi maior entre as três areias, o que é justificado devido à presença de grãos de maiores dimensões, isto é, a maior dimensão máxima característica. Essas propriedades influenciaram diretamente o comportamento das argamassas tanto no estado fresco, quanto no endurecido. Por exemplo, a maior dimensão máxima característica da AN6040 tem influência sobre a resistência mecânica das argamassas, uma vez que para a mesma relação água/aglomerante, quanto maior o tamanho dos agregados, maior será a sua resistência e, por conseguinte, maior serão as resistências mecânicas das argamassas. Existe ainda o indicativo de que maiores massas unitárias favorecem o empacotamento do esqueleto granular, resultando, assim, em misturas com menor índice de vazios e, portanto, em argamassas mais resistentes. Por outro lado, baixos módulos de finura, como é o caso da AP, resultam em argamassas com maior demanda de água para se obter o espalhamento requerido.

Tabela 5: Propriedades físicas dos AN's e AP's.

\begin{tabular}{l|l|l|l}
\hline \multirow{2}{*}{ PROPRIEDADES } & \multicolumn{2}{l}{ AREIAS ANALISADAS } & AN6040 \\
\cline { 2 - 4 } & AP & AN7030 & 2,36 \\
\hline Dimensão máxima característica $(\mathrm{mm})$ & 0,60 & 1,18 & 1,715 \\
\hline Módulo de finura & 0,988 & 1,503 & 1,490 \\
\hline Massa unitária $\left(\mathrm{kg} / \mathrm{dm}^{3}\right)$ & 1,436 & 1,505 & \\
\hline
\end{tabular}

Em relação às densidades de massa aparente das areias, observou-se uma aproximação, porém a AN7030 foi a que obteve melhor resultado e assim, possivelmente, possuirá menor número de vazios e, consequentemente, resultará em uma mistura com maior compacidade. Essa afirmação confirma os resultados obtidos por SCHUTTER e POPPE [31] nos quais a densidade aparente seca de diferentes tipos de agregados apresentou relação direta com o empacotamento das partículas, assim como com a curva granulométrica e a forma dos agregados.

\subsection{Caracterização das argamassas no estado fresco}

\subsubsection{Consumo de água}

A quantidade de água requerida para um espalhamento de $260 \mathrm{~mm}$ foi obtida por meio dos resultados apresentados no gráfico que relaciona a consistência versus o consumo de água/materiais secos, conforme pode ser observado na Figura 2. 


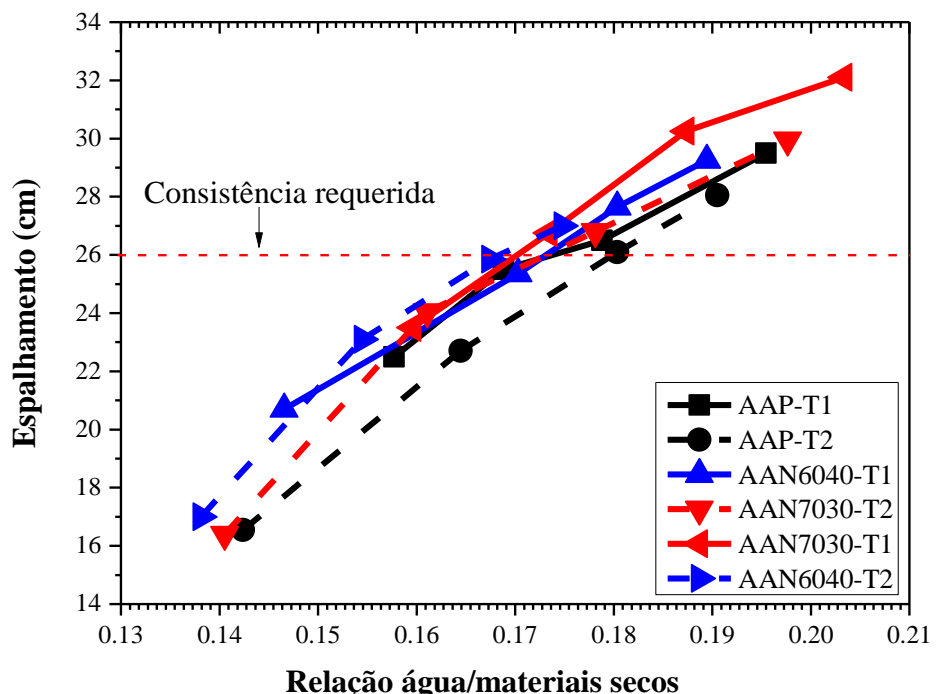

Figura 2: Consumo de água das argamassas para um espalhamento de $26 \mathrm{~cm}$.

Para o espalhamento requerido, foi necessário utilizar diferentes relações água/materiais secos, bem como diferentes quantidades de água de amassamento das argamassas com areia de praia e com as areias de rio. Os resultados são apresentados na Tabela 6.

Tabela 6: Quantidade de água requerida para a realização da mistura de consistência de $260 \mathrm{~mm}$.

\begin{tabular}{l|l|l|l|l|l|l}
\hline PROPRIEDADES & AAP-T1 & AAP-T2 & AAN6040-T1 & AAN6040-T2 & AAN7030-T1 & AAN7030-T2 \\
\hline Relação água/materiais secos & 0,174 & 0,180 & 0,173 & 0,168 & 0,170 & 0,173 \\
\hline Consumo de água $(\mathrm{g})$ & 522,0 & 540,0 & 519,0 & 504,0 & 510,0 & 519,0 \\
\hline Relação água/cimento & 2,088 & 1,440 & 2,076 & 1,344 & 2,040 & 1,384 \\
\hline Relação água/aglomerante & 0,696 & 0,720 & 0,692 & 0,672 & 0,680 & 0,692 \\
\hline
\end{tabular}

A utilização de AP, independentemente do tipo de traço utilizado, resultou em argamassas com maior demanda de água para atingir o espalhamento requerido e, portanto, em composições com maiores relações água/materiais secos, água/cimento e água/aglomerantes. Isso ocorreu possivelmente devido à maior quantidade de finos presentes nesses agregados, que, por possuírem maior superfície específica, suas misturas necessitam de maior quantidade de água para atingir o espalhamento estabelecido $(260 \mathrm{~mm})$. Associado a esse fator, tem-se que a AP possui, dentre as demais areias estudadas, menor coeficiente de uniformidade e menor densidade de massa aparente, o que leva a misturas com menor empacotamento dos grãos e, portanto, a maiores consumos de água, conforme observado por CARNEIRO [30]. Alguns estudos [7, 15] confirmam esses resultados, o que, por sua vez, tornam necessária a utilização de aditivos redutores de água para manter a relação a/c em níveis adequados visando à manutenção da consistência das argamassas. Adicionalmente, LIMEIRA et al. [15] mostraram que a maiores quantidades de AP aumentam a demanda de água para as argamassas alcançarem a consistência requerida.

Com relação às argamassas compostas por diferentes frações de $\mathrm{AN}$, verifica-se que a distribuição granulométrica e o teor de finos foram determinantes para o aumento da relação água/materiais secos e, consequentemente, dos demais parâmetros analisados. Para todas as composições estudadas com AN, a utilização da AN7030-T2 resultou em misturas com menor demanda de água, embora este agregado tenha apresentado menor coeficiente de uniformidade e maior teor de finos quando comparado ao AN6040. Porém, acredita-se que sua maior massa unitária, parâmetro muito importante para a quantificação da demanda de água em uma argamassa [31], foi determinante e conduziu a misturas mais compactas e com menor demanda de água.

\subsubsection{Densidade de massa aparente}

Analisando as densidades de massa das argamassas no estado fresco (Tabela 7), constatou-se que as argamassas com AN, no geral, obtiveram maiores massas específicas aparentes no estado fresco, sendo esse 
aumento proporcional a densidades de massa de seus agregados.

Tabela 7: Densidade de massa das argamassas no estado fresco

\begin{tabular}{l|l|l|l|l|l|l}
\hline PROPRIEDADES & AAP-T1 & AAP-T2 & AAN6040-T1 & AAN6040-T2 & AAN7030-T1 & AAN7030-T2 \\
\hline $\begin{array}{l}\text { Densidade de massa } \\
\text { aparente }\left(\mathrm{kg} / \mathrm{dm}^{3}\right)\end{array}$ & 2030,0 & 2000,0 & 2090,0 & 2080,0 & 1970,0 & 2120,0 \\
\hline
\end{tabular}

Todas as argamassas analisadas são classificadas como normais, uma vez que suas densidades de massa foram maiores que 1,40 e menores que 2,30 (segundo classificação citada por [33]) e, assim, podem ser empregadas em argamassas de revestimento.

De maneira geral, as argamassas AAP-T1 e AAN7030-T1 obtiveram menores densidades de massa no estado fresco em comparação com as demais composições. Tal fato é importante, pois, via de regra, argamassas mais leves são mais trabalháveis, o que diminui o esforço do operário e aumenta a produtividade. Esses resultados são semelhantes aos obtidos por SCHUTTER e POPPE [31] em razão das argamassas com AP e com AN apresentarem densidades de massa variando de 2,04 a 2,15 kg/dm . Portanto, não se observou grande influência da distribuição granulométrica dos agregados sobre a densidade de massa das argamassas, e isso deve-se à semelhança entre as densidades de massa dos agregados utilizados.

\subsection{Caracterização das argamassas no estado endurecido}

\subsubsection{Coeficiente de capilaridade}

As argamassas tendem a apresentar uma maior absorção de água por capilaridade logo nas primeiras horas de realização do ensaio. Com o passar do tempo, esse efeito tende a se estabilizar e, portanto, a velocidade com que ocorre a absorção de água diminui lentamente. O parâmetro que caracteriza esse comportamento é o coeficiente de capilaridade, cujos resultados estão apresentados na Tabela 8 e confirmam que as argamassas produzidas com AP apresentaram maior absorção de água por capilaridade, o que era esperado tendo em vista o maior teor de finos e o menor coeficiente de uniformidade desses agregados, além da maior relação água/materiais secos e menor densidade de massa no estado fresco dessas misturas. A maior absorção significa que os poros capilares estão conectados ente si, pois, com o decorrer do tempo, sua absorção foi maior e mais rápida. Cabe ressaltar que esse fenômeno físico também é influenciado pela dimensão e volume dos poros, não fazendo parte da análise deste estudo.

Tabela 8: Coeficiente de capilaridade das argamassas.

\begin{tabular}{l|l|l|l|l|l|l}
\hline PROPRIEDADES & AAP-T1 & AAP-T2 & AAN6040-T1 & AAN6040-T2 & AAN7030-T1 & AAN7030-T2 \\
\hline $\begin{array}{l}\text { Coeficiente de capilari- } \\
\text { dade }\left(\mathrm{kg} / \mathrm{m}^{2} \cdot \mathrm{min}^{1 / 2}\right)\end{array}$ & 0,784 & 0,663 & 0,480 & 0,580 & 0,520 & 0,600 \\
\hline
\end{tabular}

Com exceção das argamassas com AP, observou-se que a utilização do T1 conduziu a argamassas com menor absorção de água por capilaridade, independentemente do tipo de mistura utilizada (AN7030 ou AN6040). O efeito de microenchimento proporcionado pela maior quantidade de cal favorece a compacidade da mistura e a diminuição da absorção da capilaridade das argamassas. No caso das argamassas produzidas com AP, o maior consumo de cal não teve efeito nessa propriedade.

Além da capacidade de criar compostos, a água possui a capacidade de degradar os materiais naturais e artificias [34]. Assim, valores baixos de absorção sugerem argamassas mais duráveis e, portanto, as argamassas produzidas com AN6040 e com o T1, possivelmente, serão mais duráveis.

Sendo assim, nota-se que a utilização de AP, sobretudo em função de sua composição granulométrica, conduz a argamassas mais permeáveis e menos duráveis, especialmente quando o seu uso for destinado a ambientes externos.

\subsubsection{Variação de massa}

A variação de massa ocorre devido a um processo físico em que a água de amassamento evapora. Esse processo ocorre de forma mais intensa nas primeiras idades e, com o tempo, tende a se estabilizar, como pode-se observar nas curvas da Figura 3. Esse parâmetro, denominado de taxa de variação de massa (dm/dt), avalia o comportamento das argamassas quanto à perda e ao ganho de massa durante o seu endurecimento. 


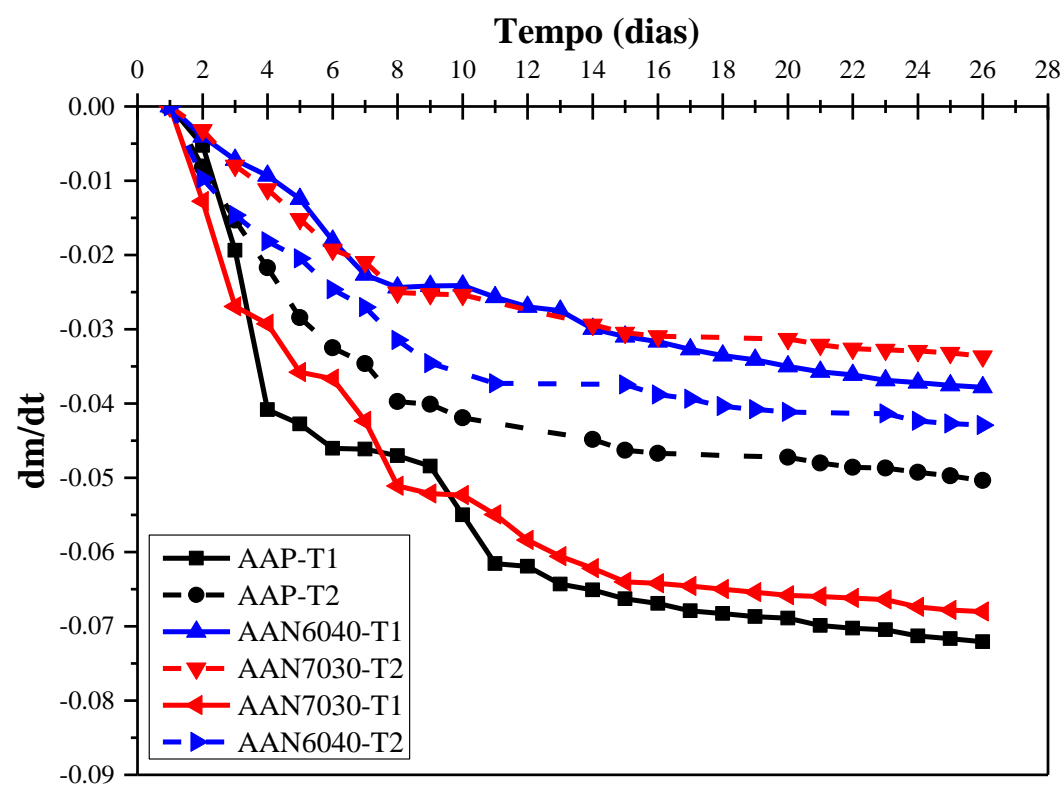

Figura 3: Curvas da variação de massa das argamassas em relação ao tempo.

No geral, as argamassas que apresentaram maior variação de massa (dm/dt), isto é, menor capacidade de retenção de água ao longo de um período de 28 dias foram as com AP (AAP-T1 e AAP-T2). Estas, independentemente do traço utilizado, possuem menor capacidade de reter água em seu interior devido às maiores relações a/c e à menor densidade de massa no estado fresco. O resultado de tais características no estado fresco contribui para a obtenção de argamassas mais porosas no estado endurecido, consequentemente apresentando menor capacidade de reter água. A exceção é a AAN7030-T1, que apresentou a segunda maior taxa de variação de massa que, possivelmente, pode estar associada à sua menor densidade de massa no estado fresco.

\subsubsection{Resistência à compressão e à tração na flexão}

Os resultados das resistências à compressão $\left(f_{c}\right)$ e à tração na flexão $\left(f_{t}\right)$ das argamassas estudadas estão listados na Tabela 8 e indicam que, independentemente do tipo de agregado utilizado, as argamassas produzidas com o T2 apresentaram maiores resistências mecânicas $\left(f_{c}\right.$ e $\left.f_{t}\right)$ em função não apenas da composição granulométrica dos agregados, mas também devido às suas menores relações a/c. Era esperado que a utilização da AP resultasse em argamassas com menores resistências quando comparada às demais, no entanto, essas misturas apresentaram boas resistências, sendo, inclusive, superiores às das misturas produzidas com AN e com T1. Possivelmente, a menor quantidade de partículas de argila ligadas à superfície da AP aumenta a ligação entre o cimento e o agregado [13], o que justifica o bom desempenho mecânico das argamassas produzidas com esses agregados.

Tabela 9: Resistências à compressão e à tração na flexão das argamassas estudadas.

\begin{tabular}{l|l|l|l|l}
\hline ARGAMASSAS & $\mathbf{f}_{\mathbf{c}}(\mathbf{M P a})$ & $\mathbf{D P}(\mathbf{M P a})$ & $\mathbf{f}_{\mathbf{t}}(\mathbf{M P a})$ & $\mathbf{D P} \mathbf{( M P a})$ \\
\hline AAP-T1 & 5,41 & 0,040 & 2,26 & 0,028 \\
\hline AAP-T2 & 5,91 & 0,034 & 2,63 & 0,016 \\
\hline AAN6040-T1 & 3,97 & 0,011 & 1,55 & 0,019 \\
\hline AAN6040-T2 & 7,16 & 0,043 & 2,56 & 0,031 \\
\hline AAN7030-T1 & 4,00 & 0,022 & 1,57 & 0,010 \\
\hline AAN7030-T2 & 7,73 & 0,055 & 2,77 & 0,041 \\
\hline
\end{tabular}

DP = Desvio-padrão.

Acredita-se que a densidade de massa no estado fresco (efeito da melhor granulometria) e, possivelmente, a capacidade de retenção de água proporcionada pelo efeito de microenchimento dos finos e dos aglomerantes tenham sido determinantes para a diminuição dos vazios e, consequentemente, para esse bom desempenho. Em outras palavras, esses resultados indicam que essas argamassas apresentam uma microestru- 
tura mais densa, resultado de um arranjo adequado das partículas.

Todavia, faz-se necessária a variação da substituição da AN pela AP com a intenção de se obter níveis adequados e argamassas com melhor desempenho. A exemplo disso, LIMEIRA et al. [15] concluíram que o índice ideal de substituição de AN por AP para a produção de argamassas é de, no máximo, 25\%, ou seja, substituições maiores, como é o caso deste estudo (100\%), podem afetar a resistência mecânica das argamassas. Acredita-se ainda que o desempenho mecânico das argamassas com AP pode ter sido afetado devido à presença de cloretos $\left(\mathrm{Cl}^{-}\right)$e sulfatos $\left(\mathrm{MgSO}_{4}\right)$ nas AP's [16]. Esses íons são demasiadamente conhecidos na literatura por seu efeito de expansão, cujo resultado é o surgimento de fissuras na zona de transição entre a matriz e o agregado e, consequentemente, redução da resistência das argamassas. Esses resultados apontam para a necessidade da AP ser devidamente processada (por exemplo, lavada com água doce) a fim de se evitar o surgimento de futuras manifestações patológicas [14].

Por outro lado, as argamassas produzidas com AN e, sobretudo, com o T2 apresentaram as maiores resistências mecânicas. Alguns fatores podem estar associados ao aumento de resistência dessas composições, como, por exemplo: (i) a maior compacidade da mistura no estado anidro, resultado dos maiores coeficientes de uniformidade; (ii) as maiores densidades de massa no estado fresco, que favorecem a redução do teor de ar incorporado; (iii) a utilização de uma maior quantidade de cimento nessas argamassas, efeito da utilização do T2; (iv) e o fato dessas argamassas apresentarem baixa variação de massa (dm/dt).

A maior resistência mecânica reflete em argamassas com maior rigidez, o que não é apreciável, tendo em vista que argamassas mais rígidas não possuem capacidade de absorver deformações e, com isso, há uma maior susceptibilidade à fissuração dos revestimentos. COUTINHO, PRETTI e TRISTÃO [35] apontam que o uso excessivo de cimento na formação de argamassas pode resultar em revestimentos susceptíveis a fissuração e, na prática, a gastos desnecessários com cimento. Nesse sentido, do ponto de vista de durabilidade, as misturas produzidas com o T2 (rico em cimento) não são recomendadas para a produção de argamassas de revestimento.

\section{CONCLUSÕES}

Este trabalho analisou os efeitos da utilização de areia de praia (AP) em argamassas mistas de revestimento e buscou comparar os resultados com argamassas produzidas com areia natural (AN). A partir dos resultados experimentais e discussões acima, as seguintes conclusões podem ser extraídas:

- Estado anidro: a areia da praia apresenta um maior teor de finos em comparação com as areias de leito de rio. Em relação à distribuição granulométrica, a areia mista com diâmetro máximo de 2,36 mm (AN6040) apresentou maior coeficiente de uniformidade, sendo, portanto, a com melhor distribuição. Tal fato contribui para o melhor arranjo entre as suas partículas, o que diminui os vazios, melhorando sua compacidade e contribuindo para o aumento na resistência das argamassas;

- Estado fresco: por apresentar maior teor de finos, as argamassas com AP e a AN (AN7030), independente do traço, foram as que obtiveram a maior quantidade de água na mistura para atingir o espalhamento requerido. Os vazios que surgem pela uniformidade dos grãos e o teor de finos também influenciam a densidade das argamassas, sendo percebidos, principalmente, nas misturas com AP, pois estas apresentaram densidade menor e, por consequência, são mais leves, o que melhora a trabalhabilidade da mistura.

- Estado endurecido:

- Absorção por capilaridade: foi influenciada pela distribuição granulométrica e pela proporção dos materiais (principalmente a quantidade de cal). As argamassas com o T2 apresentaram menor absorção de água por capilaridade, possivelmente devido à cal favorecer a retenção de água de amassamento da mistura e, consequentemente, diminuir a permeabilidade à água da argamassa;

- Variação de massa: as argamassas produzidas com agregados com elevados teores de finos e com menor coeficiente de uniformidade são as que possuem menor capacidade de retenção de água de amassamento no estado endurecido. Isso deve-se aos vazios presentes na mistura, pois a água, diferentemente do que ocorre em agregados com distribuição granulométrica contínua, não se aprisiona nos interstícios dos agregados. A cal contribui para a retenção, porém, quando elevados teores são utilizados, uma argamassa de cal e cimento pode perder muita água, mas não consegue reter na mesma proporção;

- Resistência à tração na flexão e à compressão: independentemente da distribuição granulométrica, que nesse caso não influenciou significativamente nos resultados, as argamassas T2 obtiveram as maiores resistências, visto que o teor de cimento é maior quando comparado ao T1.

Os resultados indicaram que as AP's e AN's apresentam comportamentos físicos semelhantes, embora as APs possuam distribuição granulométrica mais uniforme e maior quantidade de finos. Do ponto de vista físico, essas características não justificam a restrição do uso de areias de praia em concretos e argamassas, 
desde que não haja armaduras nesses compósitos. Se utilizado algum tratamento que remova os sais, a utilização de AP surge como uma alternativa viável e com grande potencial para ser utilizada como material de construção, uma vez que a extração de AN de rio ocasiona sérios problemas ambientais.

\section{BIBLIOGRAFIA}

[1] KUlatungA, U., AMARATUNGA, D., HAIGH, R., "Attitudes and perceptions of construction workforce on construction waste in Sri Lanka", Management of Environmental Quality: An International Journal, v. 17, n. 1, p. 57-72, 2006.

[2] AllwOOD, J. M., ASHBY, M. F., GUTOWSKI, T. G., et al., "Material efficiency: A white paper", Resources, Conservation and Recycling, v. 55, n. 3, pp. 362-381, 2011.

[3] AGOPYAN, V., JOHN, V. M., O desafio da sustentabilidade na construção civil. In: GODEMBERG, J. (Coord.), Sustentabilidade, 1 ed., 5 v. São Paulo, Blücher, 2011.

[4] ANEPAC. "Agregados", Dados da ANEPAC, 2010, http://anepac.org.br/wp/agregados. Acesso em setembro 2017.

[5] DNPM. Sumário Mineral 2014 - Areia para Construção. Brasília, DNPM. p. 141, 2014.

[6] ALMEIDA, S. L., LUZ, A. B. Manual de agregados para construção civil, Rio de Janeiro: CETEM, 2009.

[7] LIMEIRA J., ETXEBERRIA, M., AGULLÓ, L. et al., "Mechanical and durability properties of concrete made with dredged marine sand", Construction and building materials, v. 25, n. 11, pp. 4165-4174, 2011.

[8] BEDERINA, M., MAKHLOUFI, Z., BOUNOUA, A. et al. "Effect of partial and total replacement of siliceous river sand with limestone crushed sand on the durability of mortars exposed to chemical solutions", Construction and Building Materials, v. 47, pp. 146-158, 2013.

[9] WANG, Z., ZHAO, X. L., XIAN, G. et al. "Durability study on interlaminar shear behaviour of basalt, glass-and carbon-fibre reinforced polymer (B/G/CFRP) bars in seawater sea sand concrete environment”, Construction and Building Materials, v. 156, pp. 985-1004, 2017.

[10] RODRIGUES, F., CARVAlHO, M. T., EVANGELISTA, L., et al., "Physical-chemical and mineralogical characterization of fine aggregates from construction and demolition waste recycling plants", Journal of Cleaner Production, v. 52, pp. 438-445. 2013.

[11] LELLES, L. C., SILVA, E., GRIFFITH, J. J., et al., "Perfil ambiental qualitativo da extração de areia em cursos d'água", Revista Árvore, v. 29, n. 3, pp. 439-444, 2005.

[12] BELFERRAG, A., KRIKER, A., ABBOUDI, S., et al., "Effect of granulometric correction of dune sand and pneumatic waste metal fibers on shrinkage of concrete in arid climates", Journal of Cleaner Production, v. 112, pp. 3048-3056, 2016.

[13] HUIGUANG, Y., YAN, L., HENGLIN, L., et al., "Durability of sea-sand containing concrete: Effects of chloride ion penetration", Mining science and technology (China), v. 21, n. 1, pp. 123-127, 2011.

[14] XIAO, J., QIANG, C., NANNI, A., et al., "Use of sea-sand and seawater in concrete construction: Current status and future opportunities", Construction and Building Materials, v. 155, pp. 1101-1111, 2017.

[15] LIMEIRA, J., AGUlló, L., ETXEBERRIA, M., "Dredged marine sand as a new source for construction materials”, Materiales de Construcción, v. 62, n. 305, pp. 7-24, 2012.

[16] TULASHIE, S. K., KOTOKA, F., MENSAH, D., et al., "Investigation of the compressive strength of pit sand, and sea sand mortar prisms produced with rice husk ash as additive", Construction and Building Materials, v. 151, p. 383-387, 2017.

[17] HASDEMIR, S., TUĞRUL, A., YILMAZ, M., "The effect of natural sand composition on concrete strength", Construction and Building Materials, v. 112, pp. 940-948, 2016.

[18] SEIF, E. S. S. A., "Performance of cement mortar made with fine aggregates of dune sand, Kharga Oasis, Western Desert, Egypt: an experimental study”, Jordan Journal of Civil Engineering, v. 7, n. 3, pp. 270-284, 2013.

[19] SUGRAÑEZ, R., ÁLVAREZ, J. I., CRUZ-YUSTA, M., et al., "Controlling microstructure in cement based mortars by adjusting the particle size distribution of the raw materials", Construction and building materials, v. 41, p. 139-145, 2013.

[20] CORTES, D. D., KIM, H. K., PALOMINO, A. M., et al., "Rheological and mechanical properties of mortars prepared with natural and manufactured sands", Cement and Concrete Research, v. 38, p. 11421147, 2008. 
[21] ASSOCIAÇÃO BRASILEIRA DE NORMAS TÉCNICAS - ABNT, NBR NM 45: Agregados Determinação de massa unitária e do volume de vazios, Rio de Janeiro, 2006.

[22] ABNT, NBR 13276: Argamassa para assentamento e revestimentos de paredes e tetos - Preparo da mistura e determinação do índice de consistência, Rio de Janeiro, 2005.

[23] ABNT, NBR NM 248: Agregados - Determinação da composição granulométrica, Rio de Janeiro, 2003.

[24] ABNT, NBR 13278: Argamassa para assentamento e revestimento de paredes e tetos - Determinação da densidade de massa e do teor de ar incorporado, Rio de Janeiro, 2005.

[25] ABNT, NBR 15259: Argamassa para assentamento e revestimento de paredes e tetos - Determinação da absorção de água por capilaridade e do coeficiente de capilaridade, Rio de Janeiro, 2005.

[26] CENTRE SCIENTIFIQUE ET TECHNIQUE DU BATIMENT - C.S.T.B. Certifications des enduits monocouches d'imperméabilisation - Modalités d'essais. Livrasion 341, cahier 2669-4, juillet-août, 7p, 1993.

[27] ABNT, NBR 13279: Argamassa para assentamento e revestimento de paredes e tetos - Determinação da resistência à tração na flexão e à compressão, Rio de Janeiro, 2005.

[28] AMERICAN SOCIETY FOR TESTING AND MATERIALS - ASTM, C144-3: Standard Specification for Aggregate for Masonry Mortar, Philadelphia, United States, 2004.

[29] ABNT, NBR 7211: Agregados para concreto - especificações. Rio de Janeiro, 2009.

[30] CARNEIRO, A. M. P., Contribuição ao estudo da influência do agregado nas propriedades de argamassas compostas a partir de curvas granulométricas, Tese D.Sc., Escola Politécnica da Universidade de São Paulo, São Paulo, 1999.

[31] SCHUTTER, G., POPPE, A. M., "Quantification of the water demand of sand in mortar", Construction and Building Materials, v.18, n.7, 517-521, 2004.

[32] GLENCROSS-GRANT, R., WALKER, P. "Survey of building sands in Australia", Construction and Building Materials, v. 17, n. 4, pp. 259-268, 2003.

[33] CARASEK, H., Argamassas. Capítulo 26. In: ISAIA, Geraldo (Ed.). Materiais de Construção Civil e Princípios de Ciência e Engenharia de Materiais. 2 ed., IBRACON, v.1 \& v.2, pp. 863-891, 2010.

[34] MEHTA, P. K., MONTEIRO, P. J. M., Concreto: estrutura, propriedades e materiais. São Paulo, PINI, 2014.

[35] COUTINHO, S. M., PRETTI, S. M., TRISTÃO, F. A. "Argamassa preparada em obra x argamassa industrializada para assentamento de blocos de vedação: Análise do uso em Vitória-ES Made in site mortar X industrialized mortar for laying bricks: Review of their use in Vitória-ES”, Teoria e prática na Engenharia Civil, v.21, pp. 41-48, 2013.

\section{ORCID}

Ruan Landolfo da Silva Ferreira

Ilana Maria da Silva Barros

Túlio Cesar de Souza Costa

Mauricéia Medeiros

Maria das Vitórias Vieira Almeida de Sá

Arnaldo Manoel Pereira Carneiro https://orcid.org/0000-0001-6744-5395

https://orcid.org/0000-0002-8719-6055

https://orcid.org/0000-0002-4155-0311

https://orcid.org/0000-0003-0430-2965

https://orcid.org/0000-0002-8324-7599

https://orcid.org/0000-0002-4279-7156 